\title{
Overview of the Grapefruit Market in France ${ }^{1}$
}

\author{
Yan Heng, Mitzey Tejeda, and Lisa House ${ }^{2}$
}

\section{Introduction}

According to the United States Department of Agriculture, Foreign Agricultural Service (USDA-FAS 2018), France is the leading import market for US grapefruit in Europe. In the world market, France ranked third, following Japan and Canada, in imports of US grapefruit, at about 17.8 million pounds of grapefruit in the 2017-18 season, with a market value of US\$7.2 million.

Global consumption of and demand for grapefruit is fluctuating due to changing consumer preferences, prices, and food trends. In addition, some consumers have reduced or discontinued consuming grapefruit due to its interaction with certain medications, such as statin drugs, psychiatric drugs, and calcium channel blockers (Heng et al. 2017).

The US grapefruit industry has historically relied on fresh fruit consumption and the export market. Fresh grapefruit exports account for an average one-third of the total US fresh grapefruit utilization from 2011 to 2018 (USDA-NASS 2018). Domestic grapefruit sales in the United States totaled about \$221 million during 2017-18, of which California accounted for $36 \%$, following by Florida at $34 \%$, and Texas at $30 \%$ (USDA-NASS 2018).

The top importers of US citrus include Japan, Canada, South Korea, and the European Union (EU). Among the EU countries, France is the leading importer of US grapefruit (USDA-ERS 2018). The purpose of this report is to provide an overview of the grapefruit market in France and summarize the results of a consumer survey about grapefruit in France.

\section{Fresh Fruit Market in France}

France is the third largest economy in the European Union, with a gross domestic product (GDP) of approximately US $\$ 2.42$ trillion in 2016 (USDA-FAS 2018). The top fruits produced in France in 2017 were apples (58\%), melons $(10 \%)$, peaches and nectarines (10\%), apricots (5\%), and kiwi (5\%). France is also a net importing country of fresh fruits. In 2017, France imported 2.3 million tonnes of fresh fruit, and these imports are expected to increase (Fresh Plaza 2018a). The strong and close bilateral relationship between France and the United States provides important opportunities for US agricultural suppliers.

United States citrus accounts for about $20 \%$ in value of the total citrus imports to France (USDA-FAS 2018). France is the leading European market and the third leading world market for US grapefruit (USDA-NASS 2018). The taste of grapefruit is distinct, and French consumers demand it for its versatility. Not only is this fruit consumed for its health benefits, but there are also many food trends for the versatile grapefruit, including beverages, cocktails, savory dishes, and desserts. For example, the increase in demand for grapefruit wine heralded a wine revolution in France along with the trend to incorporate more citrus in beverages (Eater 2016).

1. This document is FE1072, one of a series of the Food and Resource Economics Department, UF/IFAS Extension. Original publication date December 2019. Visit the EDIS website at https://edis.ifas.ufl.edu for the currently supported version of this publication.

2. Yan Heng, assistant research scientist; Mitzy Tejeda, former undergraduate student; and Lisa House, professor and chair, Food and Resource Economics Department; UF/IFAS Extension, Gainesville, FL 32611.

Support for this study was provided by the Florida Department of Citrus.

The Institute of Food and Agricultural Sciences (IFAS) is an Equal Opportunity Institution authorized to provide research, educational information and other services

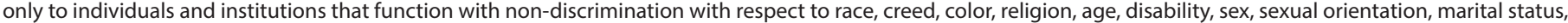
national origin, political opinions or affiliations. For more information on obtaining other UF/IFAS Extension publications, contact your county's UF/IFAS Extension office. U.S. Department of Agriculture, UF/IFAS Extension Service, University of Florida, IFAS, Florida A \& M University Cooperative Extension Program, and Boards of County Commissioners Cooperating. Nick T. Place, dean for UF/IFAS Extension. 
Demographic and socioeconomic changes affect the way in which food preferences are formed all over the world. French consumers seek high-quality products and are willing to pay more for them (USDA-FAS 2018). This gives opportunity for the United States to fulfill France's demand for high-quality grapefruit. Despite the impact of hurricanes and citrus greening on Florida's grapefruit production and market prices, France still demands Florida grapefruit, even at the higher prices (Fresh Plaza 2018b).

\section{France Grapefruit Consumer \\ Survey}

To further understand the consumption of grapefruit in France, the Florida Agricultural Market Research Center at the University of Florida conducted a national survey to evaluate trends, perceptions, and the overall impact of promotional programs by the Florida Department of Citrus for fresh grapefruit in the French market. The survey was conducted between April and May of 2018 and was completed by females 20 years old and older whose household income was at or above the 30th percentile for the country. ${ }^{1}$ To ensure data quality, one validation question was included in the survey (Jones et al. 2015). In total, data from 1,004 respondents was collected.

On average, the most important factors that influence French consumers' fresh fruit purchasing decisions include when the fruit is in season (59\%), freshness (45\%), taste (43\%), and price (43\%). About $41 \%$ of French respondents reported that they purchased grapefruit in the past six months, which is slightly lower compared to the prior year (Figure 1).

Within the group of grapefruit consumers who had purchased grapefruit in the past six months, only $1 \%$ consumed it daily. Nearly $30 \%$ consumed fresh grapefruit weekly, and about $79 \%$ of grapefruit respondents consumed grapefruit a minimum of once a month (Figure 2).

Grapefruit demand in France was relatively stable, with $57 \%$ of survey respondents who had purchased grapefruit indicating no change in purchase amount in 2018 relative to 2017 (Figure 3). Respondents also indicated a 1\% decrease and no increase in their grapefruit purchases for 2018 (21\% and $22 \%$, respectively).

Of the entire sample size, in $2018,36 \%$ preferred eating fresh grapefruit with sugar sprinkled on top, compared to $32 \%$ who preferred eating it plain with no sugar. About one-quarter (26\%) preferred squeezing the fruit to make juice (Figure 4). Another 11\% indicated they did not know

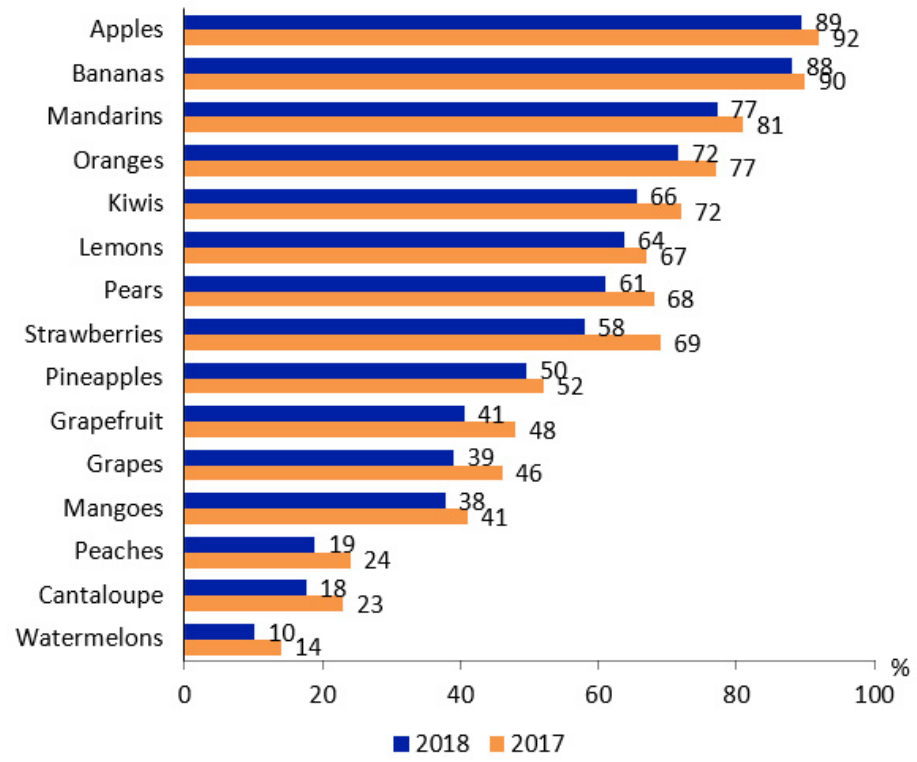

Figure 1. Grapefruit purchase rate over the past six months (\%) by French consumers, 2017 and 2018.

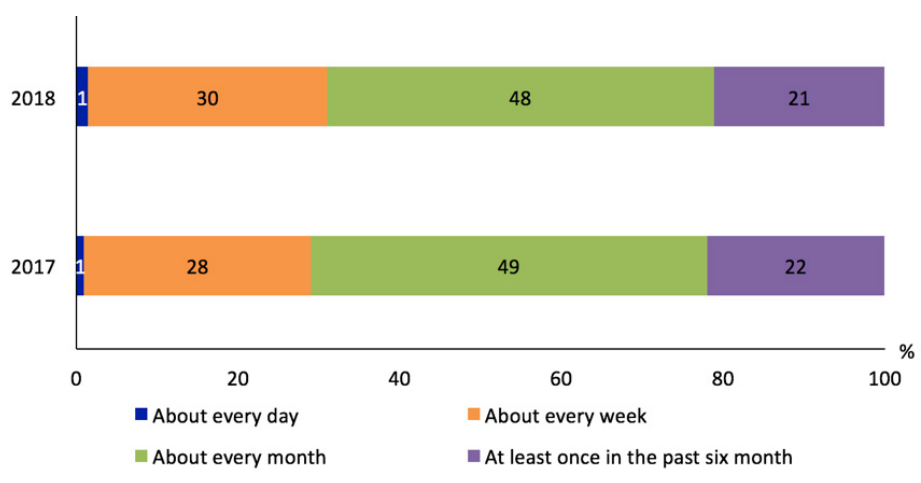

Figure 2. Consumption frequency over the last six months, 2017 and 2018.

how to eat fresh grapefruit. This is consistent with the

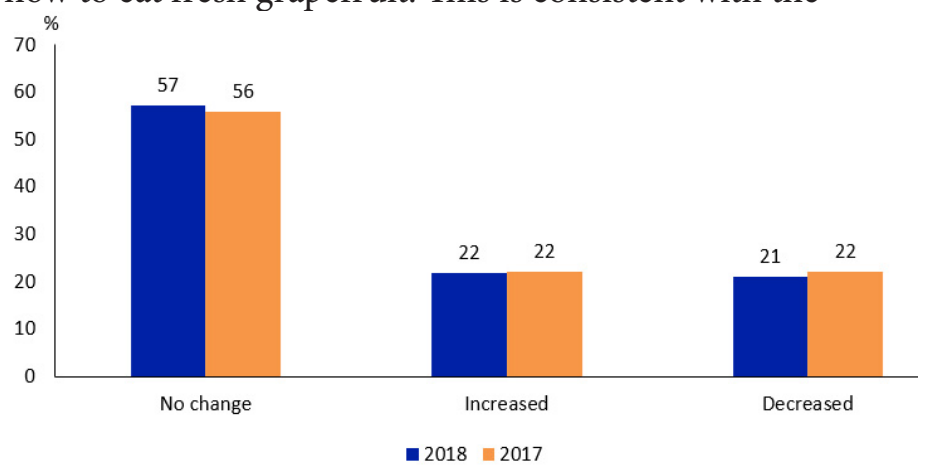

Figure 3. Changes in grapefruit purchases.

prior year and shows an opportunity for potential demand growth through education. 


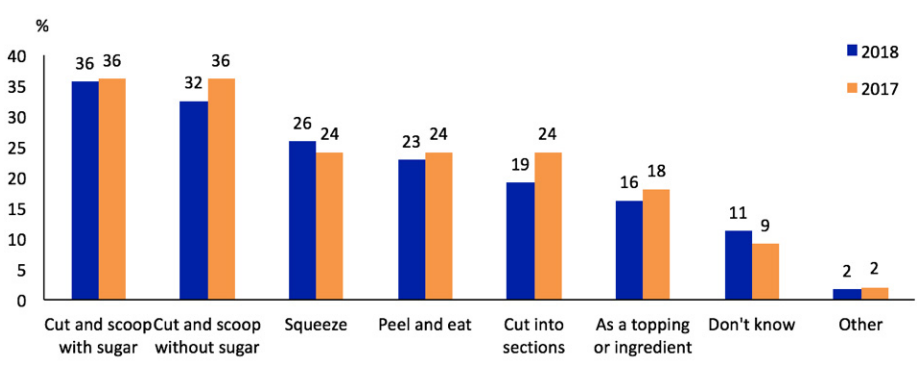

Figure 4. Fresh grapefruit usage preference, 2017 and 2018.

In relation to grapefruit trends in France, 23\% of respondents shared that in the past six months, they had consumed a juice or smoothie that contained freshsqueezed grapefruit juice (Figure 5). An additional 10\% had consumed an alcoholic beverage mixed with fresh-squeezed grapefruit juice, and about 7\% had consumed beer that had fresh-squeezed grapefruit mixed in it.

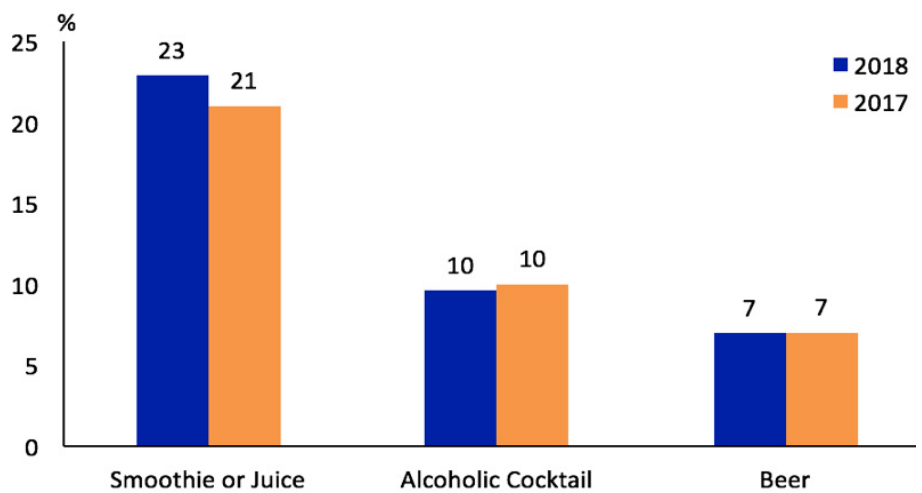

Figure 5. Consumption of fresh grapefruit juice, 2017 and 2018.

Regarding production origins, over half of the respondents were aware that Florida is a grapefruit-growing region (Figure 6), a proportion higher than for any other region/ country. Also, $37 \%$ of the grapefruit consumers indicated they purchased grapefruit from Florida (Figure 7), again a higher proportion than for any other region/country. These results indicate that French consumers are familiar with Florida grapefruit.

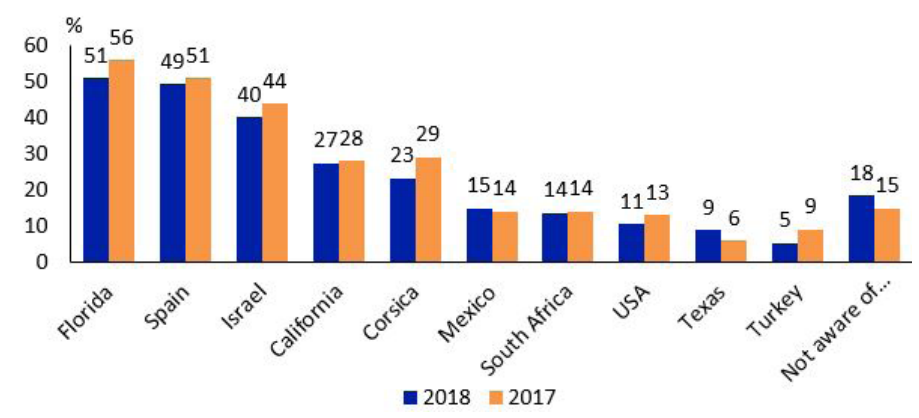

Figure 6. Aided awareness of grapefruit production regions worldwide, 2017 and 2018.

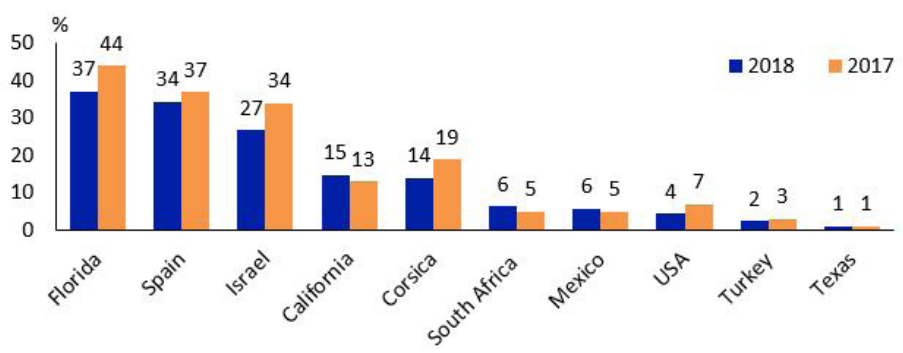

Figure 7. Aided awareness of the origin of purchased grapefruit, 2017 and 2018 .

\section{Implications}

Overall, French respondents were interested in grapefruit, with more than half indicating they are willing to purchase grapefruit in the upcoming year. The major reasons for consumers to purchase more grapefruit are that they like the fruit, believe it contributes to eating healthy, and that there are nutritional benefits. These results suggest an overall positive image held by French consumers for grapefruit. As a major supplier, well-recognized for providing high-quality products, Florida has the opportunity to continue exporting grapefruit to France. One opportunity for expansion of demand may be education about ways to consume grapefruit because $11 \%$ of respondents indicated they didn't know how to consume this fruit. Moreover, the increasing French consumption of beverages containing grapefruit juice could represent an opportunity for grapefruit producers to expand the market.

\section{Notes}

${ }^{1}$ These criteria are specified by the Florida Department of Citrus (with which this survey was conducted) because females are usually the primary shoppers, and grapefruit shoppers tend to have a relatively high income level.

\section{References}

Eater. 2016. "Grapefruit Wine Is France's Latest Obsession." Eater.com. https://www.eater.com/2016/4/19/11456746/ wine-rose-cocktail-grapefruit-france

Fresh Plaza. 2018a. "France is a Net Importer of Fresh Fruit and Vegetables." https://www.freshplaza.com/article/2192984/ france-is-a-net-importer-of-fresh-fruit-and-vegetables/.

Fresh Plaza. 2018b. "French Still Want Florida Grapefruit Regardless of High Prices." Freshplaza.com. http://www. freshplaza.com/article/2188364/french-still-want-floridagrapefruit-regardless-of-high-prices/ 
Heng, Y., H. Kim, and L. House. 2017. An Overview of the Grapefruit Market in South Korea. FE1003. Gainesville: University of Florida Institute of Food and Agricultural Sciences. http://edis.ifas.ufl.edu/fe1003

Jones, M., L. House, and Z. Gao. 2015. "Respondent Screening and SARP: Testing Quarantining Methods for Better Data Quality in Web Panel Surveys." Public Opinion Quarterly 79(3):687-709.

United States Department of Agriculture Economic Research Service (USDA-ERS). 2018. Fruit and Tree Nut Data. USDA-ERS, Washington, DC. Available at: https://data.ers. usda.gov/reports.aspx?programArea=fruit\&stat_year=2009 \&top $=5 \&$ HardCopy $=$ True $\&$ RowsPerPage $=25 \&$ groupName $=$ Citrus $\&$ commodityName $=$ Grapefruit $\& I D=17851 \#$ P07a74 07b69d24192ad4f08b6835f16ad_5_652

United States Department of Agriculture, Foreign Agricultural Service (USDA-FAS). 2018. France Exporter Guide. USDA-FAS, Washington, DC. Available at: https://gain.fas. usda.gov/Recent\%20GAIN\%20Publications/Exporter\%20 Guide_Paris_France_1-19-2018.pdf

United States Department of Agriculture, National Agricultural Statistics Service (USDA-NASS). 2018. Citrus Fruit 2018 Summary. USDA-NASS, Washington, DC. Available at: https://www.nass.usda.gov/Publications/Todays_Reports/reports/cfrt0818.pdf 